\title{
On the Thermodynamics of antioxidant action of naturally occurring hydroxyderivatives of cis-cinnamic acid
}

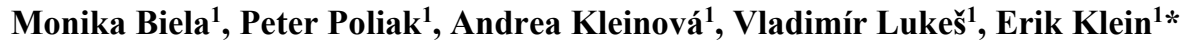 \\ ${ }^{1}$ Institute of Physical Chemistry and Chemical Physics, Slovak University of Technology in \\ Bratislava, 9 Radlinského Street, SK-812 37 Bratislava, Slovakia \\ e-mail: erik.klein@stuba.sk,monika.biela@stuba.sk,peter.poliak@stuba.sk, \\ andrea.kleinova@stuba.sk, vladimir.lukes@stuba.sk \\ *corresponding author
}

\begin{abstract}
Antioxidant activity represents one of the important features of phenolic acids, such as hydroxyderivatives of cinnamic acid. However, in the case of cis-cinnamic acid derivatives, corresponding thermochemistry data can be still considered scarce. This work is focused on the two most relevant mechanisms of primary antioxidant action in gas-phase, non-polar benzene and in aqueous solution. Reaction enthalpies describing thermodynamics of Hydrogen Atom Transfer (HAT) and Sequential Proton-Loss - Electron Transfer (SPLET) mechanisms were theoretically investigated using (SMD) M06-2X/6-311++G(d,p) method for cis-ortho-coumaric, cis-meta-coumaric, cis-para-coumaric, cis-ferulic, cis-sinapic and cis-caffeic acid and their carboxylate anions. The effect of carboxyl $\mathrm{COOH}$ group deprotonation on the thermodynamics of studied mechanisms was assessed for the three environments.
\end{abstract}

Keywords: Phenolic acid, DFT; hydrogen atom transfer; sequential proton-loss - electron transfer

\section{Introduction}

Naturally occurring phenolic acids can be divided into two groups, hydroxybenzoic acids and hydroxycinnamic acids. From the chemical point of view, these compounds have attached at least one $\mathrm{OH}$ group to aromatic ring. Hydroxyderivatives of cinnamic acid (Fig. 1), as well as other natural phenolic compounds, represent secondary plant metabolites. They are a part of human diet and show various beneficial biological effects (Heleno et al., 2015; Saxena et al., 2012).

Antioxidant (radical scavenging) activity of phenolic acids belongs to their most important effects. There are three generally accepted mechanisms of primary antioxidant action of phenolic compounds: (i) Hydrogen Atom Transfer (HAT), (ii) Single-Electron Transfer Proton Transfer (SET-PT) and (iii) Sequential Proton-Loss - Electron Transfer mechanism (SPLET) (Galano et al., 2016). Due to the presence of carboxyl group, these compounds are weak acids with first $\mathrm{p} K_{\mathrm{a}}$ values between 4.25 and 4.56 (Ozkorucuklu et al., 2009). Depending on conditions, phenolic acids can be partially or fully dissociated in aqueous solutions. 
Deprotonation may affect the radical scavenging activity, as it was shown for various (poly)phenolic substances (Amić et al., 2018 and 2020; DiMeo et al., 2013; Estevéz et al., 2010; Klein et al., 2016; Lemańska et al., 2001).<smiles>O=C(O)/C=C\c1ccccc1O</smiles>

ortho-coumaric acid<smiles>COc1cc(/C=C\C(=O)O)ccc1O</smiles>

ferulic acid<smiles>O=C(O)/C=C\c1cccc(O)c1</smiles>

meta-coumaric acid<smiles>COc1cc(/C=C\C(=O)O)cc(OC)c1O</smiles>

sinapic acid<smiles>O=C(O)/C=C\c1ccc(O)cc1</smiles>

para-coumaric acid

Fig. 1. Investigated derivatives of cis-cinnamic acid

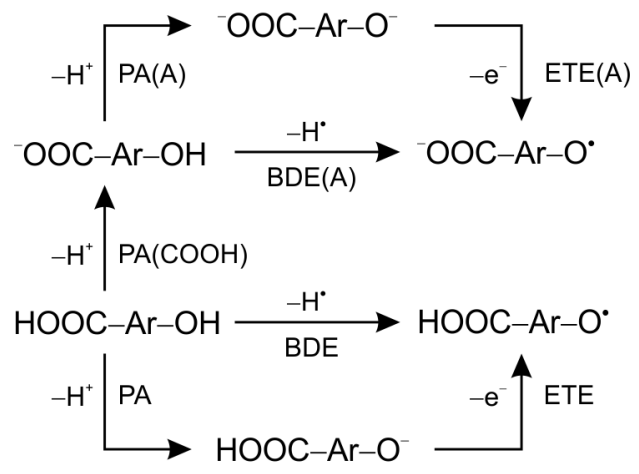

Scheme 1. Studied processes and denotations of reaction enthalpies

In nature, cinnamic acid derivatives are mainly present as trans-isomers, therefore most publications are focused on them (Amić et al., 2018; Chen et al., 2015; Koroleva et al., 2014; Mazzone et al., 2016). Thus, in this paper we decided to investigate the thermochemistry of homolytic and heterolytic cleavage of the phenolic $\mathrm{O}-\mathrm{H}$ bonds of cis-cinnamic acid hydroxyderivatives (HOOC-Ar-OH) and their carboxylate anions ( $\left.{ }^{-} \mathrm{OOC}-\mathrm{Ar}-\mathrm{OH}\right)$. Our attention is focused on $(i)$ HAT

$$
\mathrm{HOOC}-\mathrm{Ar}-\mathrm{OH} \rightarrow \mathrm{HOOC}-\mathrm{Ar}-\mathrm{O}^{\bullet}+\mathrm{H}^{\bullet}
$$




$$
{ }^{-} \mathrm{OOC}-\mathrm{Ar}-\mathrm{OH} \rightarrow{ }^{-} \mathrm{OOC}-\mathrm{Ar}-\mathrm{O}^{\bullet}+\mathrm{H}^{\cdot}
$$

and (ii) SPLET mechanisms (Scheme 1)

$$
\begin{gathered}
\mathrm{HOOC}-\mathrm{Ar}-\mathrm{OH} \rightarrow \mathrm{HOOC}-\mathrm{Ar}-\mathrm{O}^{-}+\mathrm{H}^{+} \\
-\mathrm{OOC}-\mathrm{Ar}-\mathrm{OH} \rightarrow{ }^{-} \mathrm{OOC}-\mathrm{Ar}-\mathrm{O}^{-}+\mathrm{H}^{+} \\
\mathrm{HOOC}-\mathrm{Ar}-\mathrm{O}^{-} \rightarrow \text { HOOC}-\mathrm{Ar}-\mathrm{O}^{-}+\mathrm{e}^{-} \\
-{ }^{-} \mathrm{OOC}-\mathrm{Ar}-\mathrm{O}^{-} \rightarrow{ }^{-} \mathrm{OOC}-\mathrm{Ar}-\mathrm{O}^{-}+\mathrm{e}^{-}
\end{gathered}
$$

In eqs. $1-6, \mathrm{HOOC}-\mathrm{Ar}-\mathrm{O}^{\bullet}$ stands for phenoxy radical formed from parent non-dissociated acid, ${ }^{-} \mathrm{OOC}-\mathrm{Ar}-\mathrm{O}^{\bullet}$ is radical anion formed in HAT from carboxylate anion and ${ }^{-} \mathrm{OOC}-\mathrm{Ar}-\mathrm{O}^{-}$ represents the dianion with the two functional groups deprotonated. HAT and SPLET represent dominant pathways of phenolic antioxidants radical scavenging action (Amić et al., 2018 and 2020, Chen et al., 2015; DiMeo et al., 2013; Filipović at al., 2015; Klein et al., 2017; Lengyel et al., 2013; Marković et al. 2016, Škorňa et al., 2016a). According to our best knowledge, a comprehensive study of the thermodynamics of the two mechanisms in non-polar and polar aqueous environment for hydroxyderivatives of cis-cinnamic acid and their carboxylate anions is still missing. Therefore, the main aim of this work is to calculate relevant reaction enthalpies for parent acids and their deprotonated forms and analyze the effect of structural distinctions and environment affecting the thermochemistry of their primary antioxidant action. Following derivatives of cis-cinnamic acid were studied: ortho-coumaric acid, meta-coumaric acid, paracoumaric acid, ferulic acid, sinapic acid and caffeic acid (Fig. 1).

The next section of this report presents computational details. First part of Results and Discussion is focused on HAT mechanism for non-dissociated acids and the carboxylate anions in studied environments; the second part is devoted to SPLET mechanism. Based on obtained data, thermodynamically preferred mechanism is assessed for both, acids and their carboxylate anions. Finally, comparison of our results with available data is provided. In Conclusions, most important findings are summarized.

\section{Computational details}

Quantum chemical calculations were performed in Gaussian 09 program package (Frisch et al., 2013). Hybrid functional M06-2X recommended for calculations of thermochemistry of organic compounds (Zhao and Truhlar, 2008) was employed in this work. For all calculations, 6$311++G(d, p)$ basis set was employed (Hariharan and Pople, 1973; Rassolov et al., 1998). This basis set including diffusion and polarization functions provides reliable description of studied species. The energy cut-off was $10^{-5} \mathrm{~kJ} \mathrm{~mol}^{-1}$ and final RMS energy gradient under $0.01 \mathrm{~kJ}$ $\mathrm{mol}^{-1} \AA^{-1}$. Vibrational analysis confirmed that found species are in real energy minima (no imaginary frequencies). SMD (Solvation Model based on the quantum mechanical charge Density of a solute molecule interacting with a continuum) approach (Marenich et al., 2009) was used to compute solution-phase optimum geometries and the total enthalpies of studied species in benzene (mimicking non-polar environment) and water. From the total enthalpies of molecules, radicals, anions, radical anions and dianions, these reaction enthalpies (see Scheme 1 for used denotations) were determined

$$
\begin{gathered}
\mathrm{BDE}=H\left(\mathrm{HOOC}-\mathrm{Ar}-\mathrm{O}^{\bullet}\right)+H\left(\mathrm{H}^{\bullet}\right)-H(\mathrm{HOOC}-\mathrm{Ar}-\mathrm{OH}) \\
\mathrm{BDE}(\mathrm{A})=H\left({ }^{-} \mathrm{OOC}-\mathrm{Ar}-\mathrm{O}^{\bullet}\right)+H\left(\mathrm{H}^{\bullet}\right)-H\left({ }^{-} \mathrm{OOC}-\mathrm{Ar}-\mathrm{OH}\right) \\
\mathrm{PA}=H\left(\mathrm{HOOC}-\mathrm{Ar}-\mathrm{O}^{-}\right)+H\left(\mathrm{H}^{+}\right)-H(\mathrm{HOOC}-\mathrm{Ar}-\mathrm{OH})
\end{gathered}
$$




$$
\begin{gathered}
\mathrm{PA}(\mathrm{A})=H\left({ }^{-} \mathrm{OOC}-\mathrm{Ar}-\mathrm{O}^{-}\right)+H\left(\mathrm{H}^{+}\right)-H\left({ }^{-} \mathrm{OOC}-\mathrm{Ar}-\mathrm{OH}\right) \\
\mathrm{PA}(\mathrm{COOH})=H\left({ }^{-} \mathrm{OOC}-\mathrm{Ar}-\mathrm{OH}\right)+H\left(\mathrm{H}^{+}\right)-H(\mathrm{HOOC}-\mathrm{Ar}-\mathrm{OH}) \\
\mathrm{ETE}=H\left(\mathrm{HOOC}-\mathrm{Ar}-\mathrm{O}^{\bullet}\right)+H\left(\mathrm{e}^{-}\right)-H\left(\mathrm{HOOC}-\mathrm{Ar}-\mathrm{O}^{-}\right) \\
\mathrm{ETE}(\mathrm{A})=H\left({ }^{-} \mathrm{OOC}-\mathrm{Ar}-\mathrm{O}^{\bullet}\right)+H\left(\mathrm{e}^{-}\right)-H\left({ }^{-} \mathrm{OOC}-\mathrm{Ar}-\mathrm{O}^{-}\right)
\end{gathered}
$$

In eqs. $7-13, H\left(\mathrm{H}^{+}\right)$is the calculated total enthalpy of the proton, $H\left(\mathrm{H}^{\bullet}\right)$ is the total enthalpy of the hydrogen atom, and $H\left(\mathrm{e}^{-}\right)$is the total enthalpy of the electron. The gas-phase M06-2X/6$311++\mathrm{G}(\mathrm{d}, \mathrm{p})$ total enthalpy of the hydrogen atom is $-1301.81 \mathrm{~kJ} \mathrm{~mol}^{-1}$, for solution-phase calculations the values of $-1305.81 \mathrm{~kJ} \mathrm{~mol}^{-1}$ (water) and $-1295.41 \mathrm{~kJ} \mathrm{~mol}^{-1}$ (benzene) were used. For proton and electron, following total enthalpies were used: $H\left(\mathrm{H}^{+}\right.$, water $)=$ $-1049,80 \mathrm{~kJ} \mathrm{~mol}{ }^{-1}, H\left(\mathrm{H}^{+}\right.$, benzene $)=-864,80 \mathrm{~kJ} \mathrm{~mol}^{-1}, H\left(\mathrm{e}^{-}\right.$, water $)=-73.86 \mathrm{~kJ} \mathrm{~mol}^{-1}$, $H\left(\mathrm{e}^{-}\right.$, benzene $)=-10.86 \mathrm{~kJ} \mathrm{~mol}^{-1}$ (Škorňa et al., 2016b). All thermodynamic quantities were computed for the temperature $T=298.15 \mathrm{~K}$.

\section{Results and discussion}

Carboxyl $\mathrm{COOH}$ group of investigated cis-derivatives of cinnamic acid can show two conformations: with carbonyl oxygen or $\mathrm{OH}$ group rotated towards the aromatic ring. The total enthalpies of the two conformers are similar, differences in the gas-phase do not exceed $7 \mathrm{~kJ} \mathrm{~mol}^{-1}$. In benzene and water, found differences are within 6 and $2 \mathrm{~kJ} \mathrm{~mol}^{-1}$, respectively. For all molecules, conformer with carbonyl oxygen oriented towards the aromatic ring shows lower total enthalpy (see the structure of para-coumaric acid in Fig. 2). Reaction enthalpies calculated for the products corresponding to the two conformations reached analogous values, i.e. in all environments, differences in BDEs and PAs for the two conformers are lower than 7 and $5 \mathrm{~kJ} \mathrm{~mol}^{-1}$, respectively. This indicates that the orientation of $\mathrm{COOH}$ group does not play a considerable role. In further text and tables, reaction enthalpies for the conformer with lower total enthalpy are presented. In tables, the lowest value in each column is set in italic.
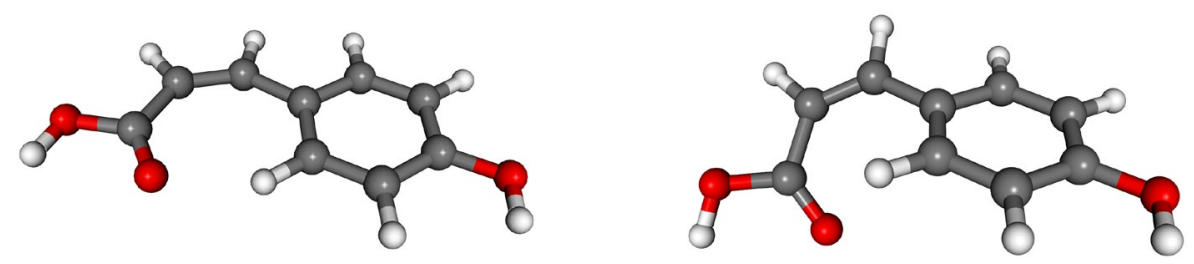

(a)

Fig. 2. Optimized structures of cis-para-coumaric acid in gas-phase (a) and water (b). Note that the side chain is not co-planar with aromatic ring in water.

In ferulic and sinapic acid, intramolecular hydrogen bond (IHB) between phenolic $\mathrm{OH}$ group and neighboring methoxy $\mathrm{OCH}_{3}$ group is present. In caffeic acid, possessing orthodihydroxy (catechol) structure, $\mathrm{O} 4-\mathrm{H} \cdots \mathrm{O} 3 \mathrm{IHB}$ is formed between the two $\mathrm{OH}$ groups. IHBs are responsible for an increase in $\mathrm{O}-\mathrm{H}$ BDE and PA values, because the abstraction of $\mathrm{H}^{\bullet}$ or $\mathrm{H}^{+}$ from the $\mathrm{OH}$ group participating in IHB requires its disruption, too. This effect is pronounced in gas-phase, in aqueous solution IHBs are considerably weaker (Michalík et al., 2019). 


\subsection{Hydrogen atom transfer mechanism}

For parent, non-dissociated molecules, differences in gas-phase and solution-phase BDE values (Table 1) are within $9 \mathrm{~kJ} \mathrm{~mol}^{-1}$ for $\mathrm{OH}$ groups which do not participate in intramolecular hydrogen bonds. With exception of para-coumaric acid, gas-phase BDEs are lower than those found for benzene and water environment. In ferulic acid, IHB formed between $\mathrm{OH}$ and $\mathrm{OCH}_{3}$ groups, responsible for the rise in $\mathrm{BDE}$, is compensated with the effect of $\mathrm{OCH}_{3}$ group tending to decrease $\mathrm{O}-\mathrm{H}$ BDE. Therefore, $\mathrm{O}-\mathrm{H}$ BDE of ferulic and para-coumaric acids are in gasphase and benzene practically identical. Only in water, the $\mathrm{O}-\mathrm{H}$ BDE of ferulic acid is higher than the value found for para-coumaric acid and remains the same as in gas-phase and benzene. For sinapic acid, the decrease in BDE occurred in benzene $\left(7 \mathrm{~kJ} \mathrm{~mol}^{-1}\right)$ and water $\left(18 \mathrm{~kJ} \mathrm{~mol}^{-1}\right)$ in comparison to gas-phase. The presence of the additional $\mathrm{OCH}_{3}$ group, placed in the second ortho position to $\mathrm{OH}$ group, results in the decrease in BDE. For caffeic acid with $\mathrm{O} 4-\mathrm{H} \cdots \mathrm{O} 3$ $\mathrm{IHB}$, drop in BDE by $20 \mathrm{~kJ} \mathrm{~mol}^{-1}$ was identified in water for 4-OH group. Due to considerably weaker IHB, the two $\mathrm{OH}$ groups have similar BDEs, while in gas-phase the difference between $3-\mathrm{OH}$ and 4-OH BDEs is $33 \mathrm{~kJ} \mathrm{~mol}^{-1}$. We note that 4-OH BDE does not reflect the subsequent rotation of 3-OH group to form new $\mathrm{O} 3-\mathrm{H} \cdots \mathrm{O} 4 \mathrm{IHB}$ stabilizing the radical.

\begin{tabular}{lcccccc}
\hline \multicolumn{1}{c}{ Acid } & \multicolumn{3}{c}{$\mathrm{BDE} / \mathrm{kJ} \mathrm{mol}^{-1}$} & \multicolumn{3}{c}{$\mathrm{BDE}(\mathrm{A}) / \mathrm{kJ} \mathrm{mol}^{-1}$} \\
\hline & Gas & Benzene & Water & Gas & Benzene & Water \\
\hline cis-ortho-coumaric & 361 & 367 & 364 & 322 & 339 & 365 \\
cis-meta-coumaric & 367 & 372 & 368 & 374 & 377 & 376 \\
cis-para-coumaric & 368 & 368 & 362 & 312 & 331 & 360 \\
cis-ferulic & 367 & 367 & 368 & 320 & 332 & 344 \\
cis-sinapic & 356 & 349 & 338 & 331 & 339 & 336 \\
cis-caffeic-3-OH & 332 & 344 & 341 & 336 & 341 & 347 \\
cis-caffeic-4-OH & 365 & 369 & 345 & 327 & 337 & 344 \\
\hline
\end{tabular}

Table 1. (SMD) M06-2X/6-311++G(d,p) BDE and BDE(A) values; the lowest value is in italic

For three coumaric acids, the position of $\mathrm{OH}$ group does not affect the BDE considerably. In the case of ortho-coumaric acid, the side chain attached to the aromatic ring at adjacent carbon atom causes steric hindrance resulting in $\mathrm{OH}$ group orientation away from the side chain. The side chain induces decrease in gas-phase BDE by $9 \mathrm{~kJ} \mathrm{~mol}^{-1}$ in comparison to phenol with M06-2X/6-311++G(d,p) BDE $=370 \mathrm{~kJ} \mathrm{~mol}^{-1}$ (Michalík et al., 2019). In the case of metaand para-coumaric acids, gas-phase BDEs can be considered identical and they are higher than the value calculated for ortho-coumaric acid. In aqueous solution, para-coumaric acid shows the lowest BDE among the three acids. The environment and the position of $\mathrm{OH}$ group alter $\mathrm{BDE}$ in low extent, since all BDEs found for coumaric acids in Table 1 are in the narrow range of $11 \mathrm{~kJ} \mathrm{~mol}^{-1}$.

The presence of 4-OH group is the only structural difference between caffeic and metacoumaric acid. Second $\mathrm{OH}$ group induces significant decrease, $27-35 \mathrm{~kJ} \mathrm{~mol}^{-1}$, in $3-\mathrm{OH} \mathrm{BDE}$ of caffeic acid. The largest effect can be observed in gas-phase and the lowest difference was identified in water. In gas-phase and benzene, 3-OH BDE of caffeic acid is the lowest one among all studied compounds. In aqueous solution, the lowest BDE value shows sinapic acid. However, its BDE is lower than 3-OH BDE of caffeic acid only by $3 \mathrm{~kJ} \mathrm{~mol}^{-1}$.

The second part of Table 1 summarizes $\mathrm{BDE}(\mathrm{A})$ values calculated for carboxylate anions of investigated acids. Data in the table imply that $\mathrm{COOH}$ group deprotonation often causes drop in $\mathrm{O}-\mathrm{H}$ bond dissociation enthalpy, i.e. BDEs are larger than BDE(A) values. As it could be 
expected, the largest differences show gas-phase data. These are driven just by the electron structure of investigated species. For carboxylate anions in gas-phase, as well as in benzene, large decrease was identified for bond dissociation enthalpies of $\mathrm{OH}$ groups in ortho or para position to side chain, see values for ortho- and para-coumaric acid, ferulic acid and 4-OH group of caffeic acid. On the contrary, in all environments the rise in bond dissociation enthalpies, up to $8 \mathrm{~kJ} \mathrm{~mol}^{-1}$, is observed for $\mathrm{OH}$ groups in meta position to the side chain, e.g. in meta-coumaric acid and 3-OH group of caffeic acid. Only in benzene, 3-OH BDE(A) for caffeic acid is lower by $3 \mathrm{~kJ} \mathrm{~mol}^{-1}$ than $3-\mathrm{OH} \mathrm{BDE}$. Solvents attenuate the effect of the electron structure of studied species and $\mathrm{BDE}(\mathrm{A})$ values are closer to BDEs. In gas-phase, maximum difference of $55 \mathrm{~kJ} \mathrm{~mol}^{-1}$ was found for para-coumaric acid. In non-polar benzene, it is decreased to $35 \mathrm{~kJ} \mathrm{~mol}^{-1}$.

For aqueous solution, maximum difference in $\mathrm{BDE}$ and $\mathrm{BDE}(\mathrm{A}), 24 \mathrm{~kJ} \mathrm{~mol}^{-1}$, shows ferulic acid. This acid shows large drop in $\mathrm{O}-\mathrm{H}$ bond dissociation enthalpy upon deprotonation of $\mathrm{COOH}$ group in gas-phase $\left(47 \mathrm{~kJ} \mathrm{~mol}^{-1}\right)$ and benzene $\left(35 \mathrm{~kJ} \mathrm{~mol}^{-1}\right)$, too. For all other acids, deviations between $\mathrm{BDE}(\mathrm{A})$ and $\mathrm{BDE}$ values are within $8 \mathrm{~kJ} \mathrm{~mol}^{-1}$. Low differences between $\mathrm{BDE}$ and $\mathrm{BDE}(\mathrm{A})$ in water were also found for non-dissociated and deprotonated flavonoids (Klein et al., 2016).

Interesting trend is observable in the case of para-coumaric, ferulic and sinapic acid. With increasing number of $\mathrm{OCH}_{3}$ groups in ortho position, $\mathrm{BDE}(\mathrm{A})$ values in gas-phase and benzene are growing. However, in water, the presence of one or two $\mathrm{OCH}_{3}$ groups results in the decrease in calculated $\mathrm{BDE}(\mathrm{A})$ values from $360 \mathrm{~kJ} \mathrm{~mol}^{-1}$ for para-coumaric to $336 \mathrm{~kJ} \mathrm{~mol}^{-1}$ for sinapic acid with the lowest BDE(A) among all studied carboxylate anions in water. This trend may be in relation with the different planarity of the carboxylate anions in aqueous solution. The side chain of para-coumaric acid anion can be considered co-planar with aromatic ring, only oxygen atoms of $\mathrm{COO}^{-}$group are twisted out of the plane. In ferulic acid, whole side chain is twisted out of the aromatic ring plane. Thus, electron-withdrawing effect of $\mathrm{COO}^{-}$group may be weaker due to lower conjugation between the side chain and the aromatic ring. In the case of sinapic acid, the steric hindrance between $\mathrm{OCH}_{3}$ group and the side chain causes its considerable distortion from the planarity. Moreover, $\mathrm{OCH}_{3}$ groups, as well as weaker IHB lead to further decrease in $\mathrm{BDE}(\mathrm{A})$ of carboxylate anions of ferulic and sinapic acid. Thus, sinapic acid with two $\mathrm{OCH}_{3}$ groups has the lowest $\mathrm{BDE}(\mathrm{A})$ value in water. Water also affects partial charges of carbon atoms and oxygen atoms of $\mathrm{COO}^{-}$group (data not shown). On the other hand, $\mathrm{BDE}(\mathrm{A})$ values show opposite trend in gas-phase and benzene. In the two environments, paracoumaric acid has the lowest $\mathrm{BDE}(\mathrm{A})$. Besides, compared to aqueous solution, carboxylate anions of ferulic and sinapic acids are more planar in gas-phase and benzene.

\subsection{Proton affinities of carboxylate anions}

Table 2 summarizes calculated proton affinities of carboxylate anions $\mathrm{PA}(\mathrm{COOH})$, i.e. reaction enthalpies of acid deprotonation. All $\mathrm{PA}(\mathrm{COOH})$ values can be found in narrow ranges: 27 $\mathrm{kJ} \mathrm{mol}^{-1}$ in gas-phase, $17 \mathrm{~kJ} \mathrm{~mol}^{-1}$ in benzene and $4 \mathrm{~kJ} \mathrm{~mol}^{-1}$ in water. It confirms that substituents placed at aromatic ring do not affect the thermodynamics of $\mathrm{COOH}$ group deprotonation significantly, especially in aqueous solution. Data in Table 2 are in line with available experimental $\mathrm{p} K_{\mathrm{a}}$ values of para-coumaric, ferulic, sinapic and caffeic acid determined from capillary electrophoresis experiments by Ozkorucuklu et al. (2009). These are also in very narrow range from 4.25 to 4.34 with the estimated standard deviations from 0.03 to 0.06 . 


\subsection{Sequential proton-loss - electron transfer mechanism}

Calculated proton affinities compiled in Table 3 confirm that SPLET mechanism is thermodynamically favored in water representing polar ionization-supporting solvent. In water, proton affinities of phenolics are by ca one order lower than gas-phase values (Chen et al., 2015; Lengyel et al., 2013; Škorňa et al., 2016b; Urbaniak et al., 2013). However, gas-phase PAs enable to analyze the effect of the structure not affected by solvation induced changes. The lowest gas-phase PA was found for 3-OH group of caffeic acid with ortho-dihydroxy structure. The highest one shows meta-coumaric acid, where the effect of the side chain is weakest. On the contrary, $\mathrm{OH}$ group placed in the para position to side chain results in $41 \mathrm{~kJ} \mathrm{~mol}^{-1}$ decrease in PA of para-coumaric acid. For ortho-coumaric acid, gas-phase PA is higher only by 6 $\mathrm{kJ} \mathrm{mol}^{-1}$ compared to para-coumaric acid. All gas-phase PAs lie in $44 \mathrm{~kJ} \mathrm{~mol}^{-1}$ wide range. If one compares para-coumaric acid with ferulic acid possessing $\mathrm{OCH}_{3}$ substituent in the orthoposition to phenolic $\mathrm{OH}$ group, formed IHB results in PA larger by $22 \mathrm{~kJ} \mathrm{~mol}^{-1}$. The presence of the second $\mathrm{OCH}_{3}$ group in sinapic acid leads to drop in PA. Difference between gas-phase values of ferulic and sinapic acids is $15 \mathrm{~kJ} \mathrm{~mol}^{-1}$. Due to $\mathrm{O} 4-\mathrm{H} \cdots \mathrm{O} 3 \mathrm{IHB}$ in caffeic acid, $20 \mathrm{~kJ} \mathrm{~mol}^{-1}$ difference between 3-OH and 4-OH PAs was found.

\begin{tabular}{lccc}
\hline \multicolumn{1}{c}{ Acid } & \multicolumn{3}{c}{$\mathrm{PA}(\mathrm{COOH}) / \mathrm{kJ} \mathrm{mol}^{-1}$} \\
\hline cis-ortho-coumaric & Gas & Benzene & Water \\
cis-meta-coumaric & 1422 & 439 & 112 \\
cis-para-coumaric & 1394 & 422 & 109 \\
cis-ferulic & 1419 & 437 & 111 \\
cis-sinapic & 1422 & 437 & 112 \\
cis-caffeic & 1409 & 422 & 113 \\
\hline
\end{tabular}

Table 2. (SMD) M06-2X/6-311++G(d,p) $\mathrm{PA}(\mathrm{COOH})$ values; the lowest value is in italic

\begin{tabular}{lcccccc}
\hline \multicolumn{1}{c}{ Acid } & \multicolumn{3}{c}{$\mathrm{PA} / \mathrm{kJ} \mathrm{mol}^{-1}$} & \multicolumn{3}{c}{$\mathrm{PA}(\mathrm{A}) / \mathrm{kJ} \mathrm{mol}^{-1}$} \\
\hline & Gas & Benzene & Water & Gas & Benzene & Water \\
\hline cis-ortho-coumaric & 1390 & 426 & 146 & 1695 & 569 & 157 \\
cis-meta-coumaric & 1425 & 455 & 157 & 1736 & 597 & 164 \\
cis-para-coumaric & 1384 & 422 & 146 & 1682 & 561 & 159 \\
cis-ferulic & 1406 & 439 & 148 & 1698 & 582 & 159 \\
cis-sinapic & 1391 & 427 & 146 & 1702 & 588 & 151 \\
cis-caffeic-3-OH & 1381 & 426 & 141 & 1689 & 561 & 148 \\
cis-caffeic-4-OH & 1401 & 443 & 147 & 1705 & 579 & 158 \\
\hline
\end{tabular}

Table 3. (SMD) M06-2X/6-311++G(d,p) PA and PA(A) values; the lowest value is in italic

In benzene, PAs of studied acids are in $33 \mathrm{~kJ} \mathrm{~mol}^{-1}$ wide range. In aqueous solution they lie in narrow $16 \mathrm{~kJ} \mathrm{~mol}^{-1}$ range. If we do not consider the value of meta-coumaric acid in water, all PAs are in very narrow range from 141 to $148 \mathrm{~kJ} \mathrm{~mol}^{-1}$ confirming that water significantly diminishes differences in PA caused by the structural features of investigated compounds. Analogously to gas-phase, the lowest PA was found for 3-OH group of caffeic acid, and the largest one for meta-coumaric acid. In benzene, the lowest PA was obtained for para-coumaric acid, however, the value of $422 \mathrm{~kJ} \mathrm{~mol}^{-1}$ is close to the one for 3-OH group of caffeic acid $\left(426 \mathrm{~kJ} \mathrm{~mol}^{-1}\right)$. 
From the thermodynamics point of view, in gas-phase and non-polar benzene, HAT represents the preferred reaction pathway of non-dissociated phenolic acids. However, in agreement with other reports on phenolic acids (Amić et al., 2018; Chen et al., 2015; Urbaniak et al., 2013), SPLET represents favored mechanism in aqueous solution, because computed PAs are roughly three-times lower than BDEs.

Proton affinities PA(A) describing the thermodynamics of the first step of SPLET for phenolic $\mathrm{OH}$ groups of carboxylate anions are higher than PA ones, because the second deprotonation resulting in dianion formation is energetically more demanding. Data in Table 3 unambiguously confirm that this process can be feasible only in water. In gas-phase and benzene PA(A) values are higher by ca $300 \mathrm{~kJ} \mathrm{~mol}^{-1}$ and $140 \mathrm{~kJ} \mathrm{~mol}^{-1}$ than PA ones, respectively. On the other hand, average difference between $\mathrm{PA}(\mathrm{A})$ and $\mathrm{PA}$ values reached only $9 \mathrm{~kJ} \mathrm{~mol}^{-1}$ in aqueous solution. Thus, deprotonation of carboxylic group has only a weak effect on the heterolytic dissociation of phenolic $\mathrm{OH}$ groups in water. All PA(A) values lie in 16 $\mathrm{kJ} \mathrm{mol}^{-1}$ range - the same range was found for PAs. Analogously to PAs, the lowest and the highest $\mathrm{PA}(\mathrm{A})$ values again reached $3-\mathrm{OH}$ group of caffeic acid and meta-coumaric acid, respectively.

We can conclude that close PA and PA(A) values imply analogous tendency of nondissociated parent acids and their carboxylate anions to enter SPLET mechanism in aqueous solution. Moreover, PA(A) values are still significantly lower than BDE(A) values. Therefore, in water SPLET remains thermodynamically favored reaction pathway also for carboxylate anions.

Table 4 summarizes electron transfer enthalpies for non-dissociated derivatives of ciscinnamic acid and their carboxylate anions. Both, ETE and ETE(A) values are lowest in gasphase and largest in aqueous solution. In some cases, opposite trends between the two reaction enthalpies of SPLET can be observed: molecules with high proton affinities show lower electron transfer enthalpies and vice versa. For example, gas-phase PA of meta-coumaric acid reached the highest value and its ETE is the lowest. This trend is related to the thermodynamic cycle if one considers that initial and final states are identical in HAT and SPLET mechanisms.

\begin{tabular}{lcccccc}
\hline \multicolumn{1}{c}{ Acid } & \multicolumn{3}{c}{ ETE / kJ mol } & \multicolumn{3}{c}{ ETE(A) / kJ mol } \\
\hline & Gas & Benzene & Water & Gas & Benzene & Water \\
\hline cis-ortho-coumaric & 283 & 360 & 401 & -62 & 190 & 383 \\
cis-meta-coumaric & 252 & 339 & 394 & -51 & 200 & 387 \\
cis-para-coumaric & 295 & 366 & 398 & -58 & 189 & 375 \\
cis-ferulic & 273 & 348 & 402 & -68 & 171 & 358 \\
cis-sinapic & 276 & 343 & 375 & -60 & 170 & 359 \\
cis-caffeic-3-OH & 262 & 338 & 382 & -42 & 200 & 373 \\
cis-caffeic-4-OH & 275 & 346 & 381 & -66 & 178 & 361 \\
\hline
\end{tabular}

Table 4. (SMD) M06-2X/6-311++G(d,p) ETE and ETE(A) values; the lowest value is in italic

From the comparison of ETE and ETE(A) in Table 4, it is evident that ETE(A) values are considerably lower than ETEs in gas-phase and benzene. In gas-phase, ETE(A) values are even negative and the process is exothermic. This is again in direct relation to very high, ca 1700 $\mathrm{kJ} \mathrm{mol}^{-1}$, gas-phase PA(A) values, while PAs are by ca $300 \mathrm{~kJ} \mathrm{~mol}^{-1}$ lower. On the other hand, $\mathrm{BDEs}$ are usually higher than $\mathrm{BDE}(\mathrm{A})$ values. This trend is observable also for benzene. PA(A) values are larger than PAs, therefore ETE(A) values are lower than ETEs. Average differences reached $332 \mathrm{~kJ} \mathrm{~mol}^{-1}$ and $163 \mathrm{~kJ} \mathrm{~mol}^{-1}$ in gas-phase and benzene, respectively. In aqueous 
solution, differences between PA and PA(A) values were not very pronounced. Thus, ETE(A) values and ETEs are also similar, with $19 \mathrm{~kJ} \mathrm{~mol}^{-1}$ average difference.

\subsection{Comparison of found results with published data}

There are only two theoretical reports on cis-cinnamic acid derivatives (Koroleva et al., 2014; Urbaniak et al., 2013). Available B3LYP data for para-coumaric, ferulic and sinapic acid are compiled in Table 5. These show fair agreement with our data, though different computational approaches were employed. In general, B3LYP functional often underestimates BDE and gives remarkably lower values than M06-2X or M05-2X (Milenković et al., 2017; Marković et al., 2016; Marković and Tošović, 2016; Michalík et al., 2019; Škorňa et al., 2016b). Results of Koroleva et al. (2014) evidence that differences in gas-phase reaction enthalpies of HAT and SPLET computed for cis- and trans-cinnamic acid derivatives can reach tens of $\mathrm{kJ} \mathrm{mol}^{-1}$. Thus, found reaction enthalpies cannot be unambiguously confronted with results published for transisomers (Amić et al., 2018 and 2020; Chen et al., 2015; Marković and Tošović, 2016; Urbaniak et al., 2013). Unfortunately, there are no experimental reaction enthalpies of studied processes available. Only for non-substituted cinnamic acid, gas-phase acidity was recently determined in Dávalos et al. (2016). For $(E)$ - and $(Z)$-cinnamic acid, PA(COOH) reached values of 1428 and $1416 \mathrm{~kJ} \mathrm{~mol}^{-1}$, respectively. These are in line with M06-2X/6-311++G(d,p) values of studied derivatives in Table 2. In our previous work (Michalík et al., 2019), we have confirmed that employed computational approach provides reliable $\mathrm{O}-\mathrm{H}$ BDEs of various mono-substituted phenols. Therefore, found reaction enthalpies of HAT and SPLET mechanisms may represent relevant prediction for investigated isomers of cinnamic acid derivatives.

\begin{tabular}{llllllllll}
\hline \multicolumn{1}{c}{ Acid } & Gas & & & & \multicolumn{5}{c}{ Water } \\
\hline & BDE & BDE(A) & PA & PA(A) & ETE & ETE(A) & BDE & PA & ETE \\
\hline cis-para-coumaric & $365^{\mathrm{a}}$ & $325^{\mathrm{a}}$ & & $1676^{\mathrm{a}}$ & & $-42.3^{\mathrm{a}}$ & & & \\
cis-ferulic & $324^{\mathrm{a}}, 330^{\mathrm{b}}$ & $318^{\mathrm{a}}$ & $1400^{\mathrm{b}}$ & $1656^{\mathrm{a}}$ & $266^{\mathrm{b}}$ & $-42.3^{\mathrm{a}}$ & $338^{\mathrm{b}}$ & $128^{\mathrm{b}}$ & $335^{\mathrm{b}}$ \\
cis-sinapic & $330^{\mathrm{a}}$ & $294^{\mathrm{a}}$ & & $1680^{\mathrm{a}}$ & & $-77.6^{\mathrm{a}}$ & & & \\
\hline
\end{tabular}

${ }^{a}$ B3LYP/6-31++G(d,p) (Koroleva et al., 2014).

${ }^{\mathrm{b}}$ (C-PCM) B3LYP/6-311++G(2d,2p) (Urbaniak, et al., 2013).

Table 5. Published reaction enthalpies in $\mathrm{kJ} \mathrm{mol}^{-1}$ for gas-phase and aqueous solution

\section{Conclusions}

For six hydroxyderivatives of cis-cinnamic acid, reaction enthalpies of two radical scavenging mechanisms depicted in Scheme 1 were theoretically studied. Obtained (SMD) M06-2X/6$311++\mathrm{G}(\mathrm{d}, \mathrm{p})$ results indicate that in non-polar environment HAT is the preferred mechanism for both, acids and their carboxylate anions. Large enthalpies of $\mathrm{COOH}$ group deprotonation show that dissociation of studied acids may not play a considerable role in non-polar environment. In agreement with experimental reports, low proton affinities of carboxylate anions, $\mathrm{PA}(\mathrm{COOH})$, confirm that deprotonation of $\mathrm{COOH}$ group cannot be neglected in aqueous solution. In water, differences in reaction enthalpies computed for non-dissociated acids and their carboxylate anions are considerably lower compared to gas-phase or non-polar benzene environment. In the case of bond dissociation enthalpies, BDE and $\operatorname{BDE}(\mathrm{A})$, differences are within $8 \mathrm{~kJ} \mathrm{~mol}^{-1}$. Only cis-ferulic acid shows BDE(A) considerably lower, by $24 \mathrm{~kJ} \mathrm{~mol}^{-1}$, than BDE. As expected, PA(A) values are higher than PA ones. However, maximum difference does not exceed $13 \mathrm{~kJ} \mathrm{~mol}^{-1}$ in water. Because PA(A) values are still 
significantly lower than $\mathrm{BDE}(\mathrm{A})$ ones, in aqueous solution SPLET remains thermodynamically preferred pathway for the carboxylate anions, too. Although reaction enthalpies found for nondissociated acids and corresponding carboxylate anions reached similar values in aqueous solution, we should note that antioxidant (radical scavenging) effect is also affected by kinetics of individual processes and other factors, e.g. the type of scavenged radical, the presence of other substances or various consecutive or concurrent reactions.

Acknowledgements: The work has been supported by Slovak Grant Agency (1/0504/20) and Slovak Research and Development Agency (APVV-15-0053). We are grateful to the HPC center at the Slovak University of Technology in Bratislava, which is a part of the Slovak Infrastructure of High Performance Computing (SIVVP project, ITMS code 26230120002, funded by the European region development funds, ERDF) for the computational time and resources made available. V. L. and E. K. thank Ministry of Education, Science, Research and Sport of the Slovak Republic for funding within the scheme "Excellent research teams". This work was supported by the Slovak Research and Development Agency under the contract no. SK-SRB-18-0016.

\section{References}

Amić A, Marković Z, Dimitrić Marković J M, Milenković D, Stepanić V (2020). Antioxidative potential of ferulic acid phenoxyl radical. Phytochemistry, 170, 112218.

Amić A, Marković Z, Klein E, Dimitrić Marković, J M, Milenković D (2018). Theoretical study of the thermodynamics of the mechanisms underlying antiradical activity of cinnamic acid derivatives, Food Chem., 246, 481-489.

Chen Y, Xiao H, Zheng J, Liang G (2015). Structure-thermodynamics-antioxidant activity relationships of selected natural phenolic acids and derivatives: An experimental and theoretical evaluation. PLOS ONE, 10, e0121276.

Dávalos J Z, Lima C F R A C, Silva A M S, Santos L M N B F, Erra-Balsells R, Salum M L (2016). Energetics of neutral and deprotonated (Z)-cinnamic acid. J. Chem. Thermodyn., 95, 195-201.

Di Meo F, Lemaur V, Cornil J, Lazzaroni R, Duroux J-L, Olivier Y, Trouillas P (2013). Free radical scavenging by natural polyphenols: Atom versus electron transfer, J. Phys. Chem. $A, 117,2082-2092$.

Estevéz L, Otero N, Mosquera R A (2010). A computational study on the acidity dependence of radical-scavenging mechanisms of anthocyanidins, J. Phys. Chem. B, 114, 9706-9712.

Filipović M, Marković Z, Đorović J, Marković J D, Lučić B., Amić D (2015). QSAR of the free radical scavenging potency of selected hydroxybenzoic acids and simple phenolics, C. $R$. Chimie, 18, 492-498.

Frisch M J, Trucks G W, Schlegel H B, Scuseria G E, Robb M A, Cheeseman J R, et al. (2013). Gaussian 09, Revision D.01 Gaussian Inc, Wallingford, CT.

Galano A, Mazzone A, Alvarez-Diduk R, Marino T, Raúl Aalvarez-Idaboy J, Russo N (2016). Food Antioxidants: Chemical insights at the Molecular Level, Annu. Rev. Food Sci. Technol., 7, 15.1-15.18.

Hariharan P C, Pople J A (1973). The influence of polarization functions on molecular orbital hydrogenation energies, Theor. Chim. Acta, 28, 213-222.

Heleno S A, Martins A, Queiroz M J R P, Ferreira I C F R (2015). Bioactivity of phenolic acids: Metabolites versus parent compounds: A review, Food Chem., 173, 501-213.

Klein E, Lukeš V, Rimarčík J, Kleinová A (2017). Theoretical study of primary antioxidant action thermodynamics. J. Serbian Soc. Comput. Mech., 11, 130-138. 
Klein E, Rimarčík J, Senajová E, Vagánek A, Lengyel J (2016). Deprotonation of flavonoids severely alters the thermodynamics of the hydrogen atom transfer, Comp. Theor. Chem., $1085,7-17$.

Koroleva O, Torkova A, Nikolaev I, Khrameeva E, Fedorova T, Tsentalovich M, Amarowicz R (2014). Evaluation of the antiradical properties of phenolic acids. Int. J. Mol. Sci., 15, 16351-16380.

Lemańska K, Szymusiak H, Tyrakowska B, Zieliński R, Soffers A E M F, Rietjens I M C M (2001). The influence of $\mathrm{pH}$ on antioxidant properties and the mechanism of antioxidant action of hydroxyflavones, Free Radic. Biol. Med., 31, 869-881.

Lengyel J, Rimarčík J, Vagánek A, Klein E (2013). On the radical scavenging activity of isoflavones: Thermodynamics of $\mathrm{O}-\mathrm{H}$ bond cleavage, Phys. Chem. Chem. Phys., 15, 10895-10903.

Marenich A V, Cramer C J, Truhlar D G (2009). Universal solvation model based on solute electron density and on a continuum model of the solvent defined by the bulk dielectric constant and atomic surface tensions, J. Phys. Chem. B, 113, 6378-6396.

Marković Z, Đorović J, Dimitrić Marković J M, Biočanin R, Amić D (2016). Comparative density functional study of antioxidative activity of the hydroxybenzoic acids and their anions, Turk. J. Chem., 40, 499-509.

Marković S, Tošović J (2016). Comparative study of the antioxidative activities of caffeoylquinic and caffeic acids. Food Chem., 210, 585-592.

Mazzone G, Russo N, Toscano M (2016). Antioxidant properties comparative study of natural hydroxycinnamic acids and structurally modified derivatives: Computational insights. Comp. Theor. Chem., 1077, 39-47.

Michalík M, Poliak P, Lukeš V, Klein E (2019). From phenols to quinones: Thermodynamics of radical scavenging activity of para-substituted phenols. Phytochemistry, 166, 112077.

Milenković D, Đorović J, Jeremić S, Dimitrić Marković J M, Avdović E H, Marković Z (2017). Free Radical Scavenging Potency of Dihydroxybenzoic Acids. J. Chem., 5936239.

Ozkorucuklu S P, Beltrán J L, Fonrodona G, Barrón D, Alsancak G, Barbosa J (2009). Determination of dissociation constants of some hydroxylated benzoic and cinnamic acids in water from mobility and spectroscopic data obtained by CE-DAD, J. Chem. Eng. Data, $54,807-811$.

Rassolov V, Pople J A, Ratner M, Windus T L (1998). 6-31G* basis set for atoms K through Zn, J. Chem. Phys., 109, 1223-1229.

Saxena M, Saxena J, Pradhan A (2012). Flavonoids and phenolic acids as antioxidants in plants and human health, Int. J. Pharm. Sci. Rev. Res., 16, 130-134.

Škorňa P, Michalík M, Klein E (2016a). Gallic acid: thermodynamics of the homolytic and heterolytic phenolic O-H bonds splitting-off, Acta Chimica Slovaca, 9, 114-123.

Škorňa P, Rimarčík J, Poliak P, Lukeš V, Klein E (2016b). Thermodynamic study of vitamin B6 antioxidant potential, Comp. Theor. Chem., 1077, 32-38.

Urbaniak A, Szeląg M, Molski M (2013). Theoretical investigation of stereochemistry and solvent influence on antioxidant activity of ferulic acid. Comp. Theor. Chem., 1012, 33-40.

Zhao Y, Truhlar D G (2008). The M06 suite of density functionals for main group thermochemistry, thermochemical kinetics, noncovalent interactions, excited states, and transition elements: two new functionals and systematic testing of four M06-class functionals and 12 other functionals, Theor. Chem. Acc., 120, 215-241. 